Supporting Information

Heterojunction Perovskite Solar Cells: Opto-Electro-Thermal Physics, Modeling, and Experiment

Yidan An, ${ }^{\text {a,b,\# }}$ Changlei Wang, ${ }^{\text {a,b,\# }}$ Guoyang Cao ${ }^{\mathrm{c}}$ and Xiaofeng $\mathrm{Li}^{\mathrm{a}, \mathrm{b}, *}$

${ }^{a}$ School of Optoelectronic Science and Engineering \& Collaborative Innovation Center of Suzhou Nano Science and Technology, Soochow University, Suzhou 215006, China;

${ }^{b}$ Key Lab of Advanced Optical Manufacturing Technologies of Jiangsu Province \& Key Lab of Modern Optical Technologies of Education Ministry of China, Soochow University, Suzhou 215006, China;

${ }^{c}$ School of Science, Jiangsu Provincial Research Center of Light Industrial Optoelectronic Engineering and Technology, Jiangnan University, Wuxi 214122, China;

${ }^{\#}$ The authors contributed equally to this study

"E-mail: xfli@suda.edu.cn 


\section{Additional Figures}

\section{Characterization of Perovskite Film.}

In order to check the bandgap of the $(\mathrm{MA})_{0.7}(\mathrm{FA})_{0.3} \mathrm{PbI}_{3}$ material, the steady-state photoluminescence (PL) intensity is measured, as shown in Figure S1. The peak wavelength of PL intensity is $790 \mathrm{~nm}$, demonstrating that the bandgap of $(\mathrm{MA})_{0.7}(\mathrm{FA})_{0.3} \mathrm{PbI}_{3}$ perovskite material is $1.57 \mathrm{eV}$.

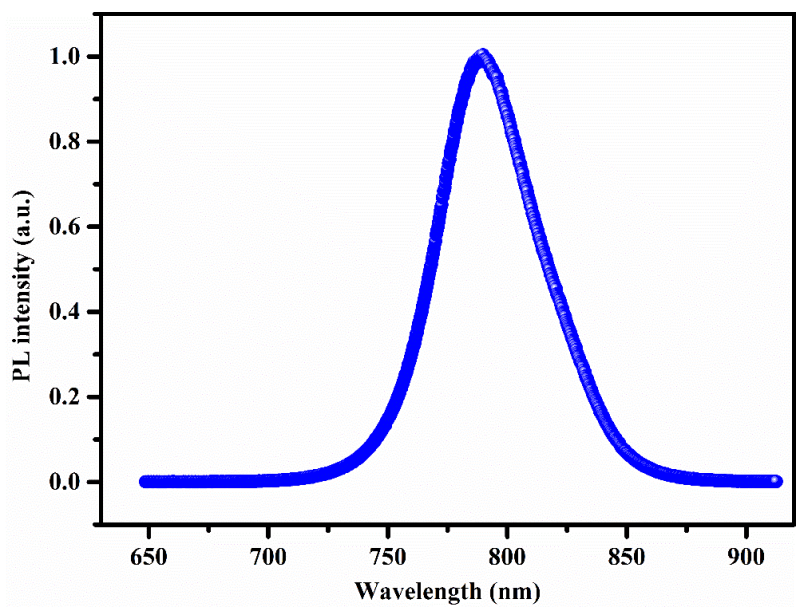

Figure S1. Steady-state photoluminescence spectrum of $\mathrm{MA}_{0.7} \mathrm{FA}_{0.3} \mathrm{PbI}_{3}$ perovskite film.

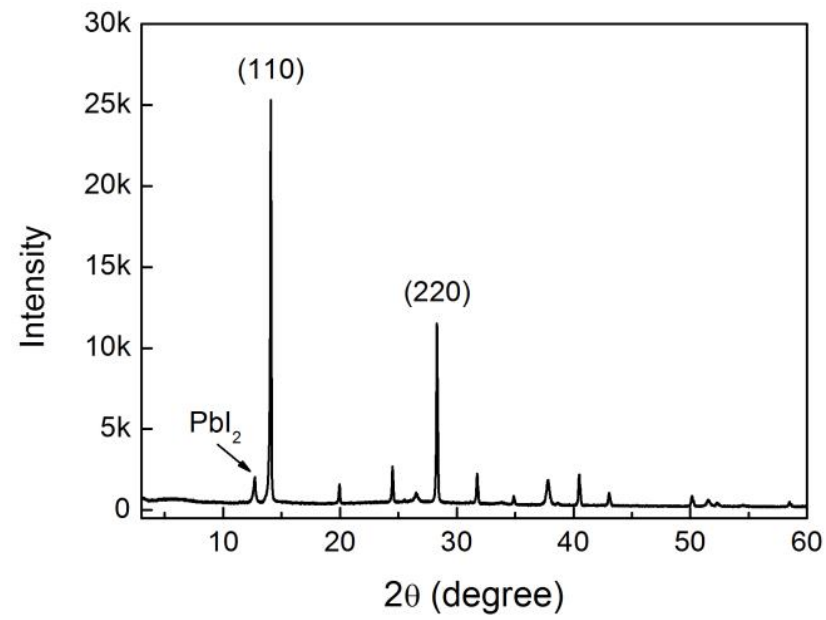

Figure S2. X-photoelectron spectroscopy (XRD) spectrum of $\mathrm{MA}_{0.7} \mathrm{FA}_{0.3} \mathrm{PbI}_{3}$ perovskite film.

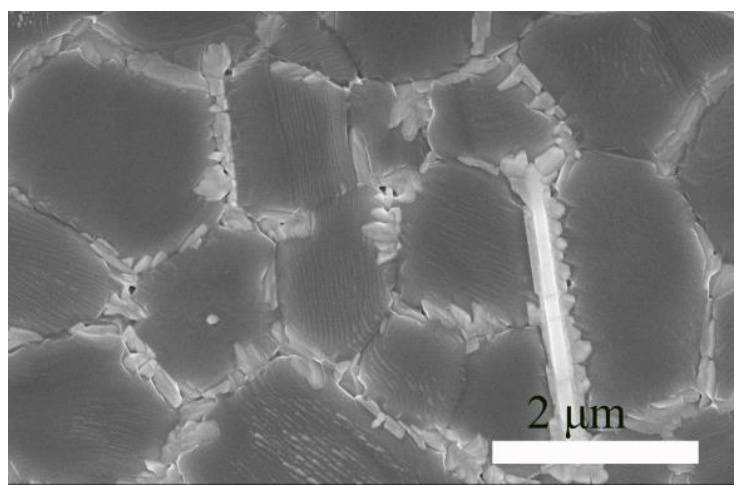

Figure S3. Top-view SEM image of $\mathrm{MA}_{0.7} \mathrm{FA}_{0.3} \mathrm{PbI}_{3}$ perovskite film, which shows the dense and large grain sizes. 


\section{Temperature Effect on the Performance of PSC.}

Actually, if we discuss the fundamental photovoltaic issues from the energy perspective, the current-voltage curve exhibits that the varying electric bias leads to the rapid variation of the output power of the SC, revealing that the energy components (electric output and thermal parts) within the device are strongly bias-dependent. Therefore, the operating temperature of PSC would be strongly affected by the electric bias.

Under the given ambient conditions (i.e., the ambient temperature of $25{ }^{\circ} \mathrm{C}$ and heat conduction-convection exchange coefficient of $\left.12 \mathrm{~W} / \mathrm{m}^{2} / \mathrm{K}\right),{ }^{1}$ Figure $\mathrm{S} 4(\mathrm{a})$ indicates that the lowest operating temperature $\left(\sim 49.79{ }^{\circ} \mathrm{C}\right)$ of our PSC is achieved at the maximum power point of PSC. By coupling the temperature in the Shockley-Queisser (SQ) model, ${ }^{2}$ we also perform the corresponding OET simulation for the ideal PSC. Based on the assumption that the radiatively recombined carriers are reabsorbed by the PSC for heating, it can be seen that the operating temperature of an ideal PSC is higher than that of the discussed PSC at low bias region due to the higher thermalization heat, however, the operating temperature of ideal PSC reaches only $47.83{ }^{\circ} \mathrm{C}$ at maximum power point. Figure S4(b) compares the J-V characteristics of ideal and our PSCs at ambient temperature and their real temperatures, respectively. It shows that the high working temperature, which addresses the realistic situation, remarkably decreases $V_{\mathrm{oc}}$ and PCE. Therefore, if considering the temperature effect, the PCE of our PSC decreases from $21.37 \%$ to $20.50 \%$. Moreover, the (upper-limit) PCE of the PSC predicted by the SQ analysis drops from $31.16 \%$ to $30.37 \%$.
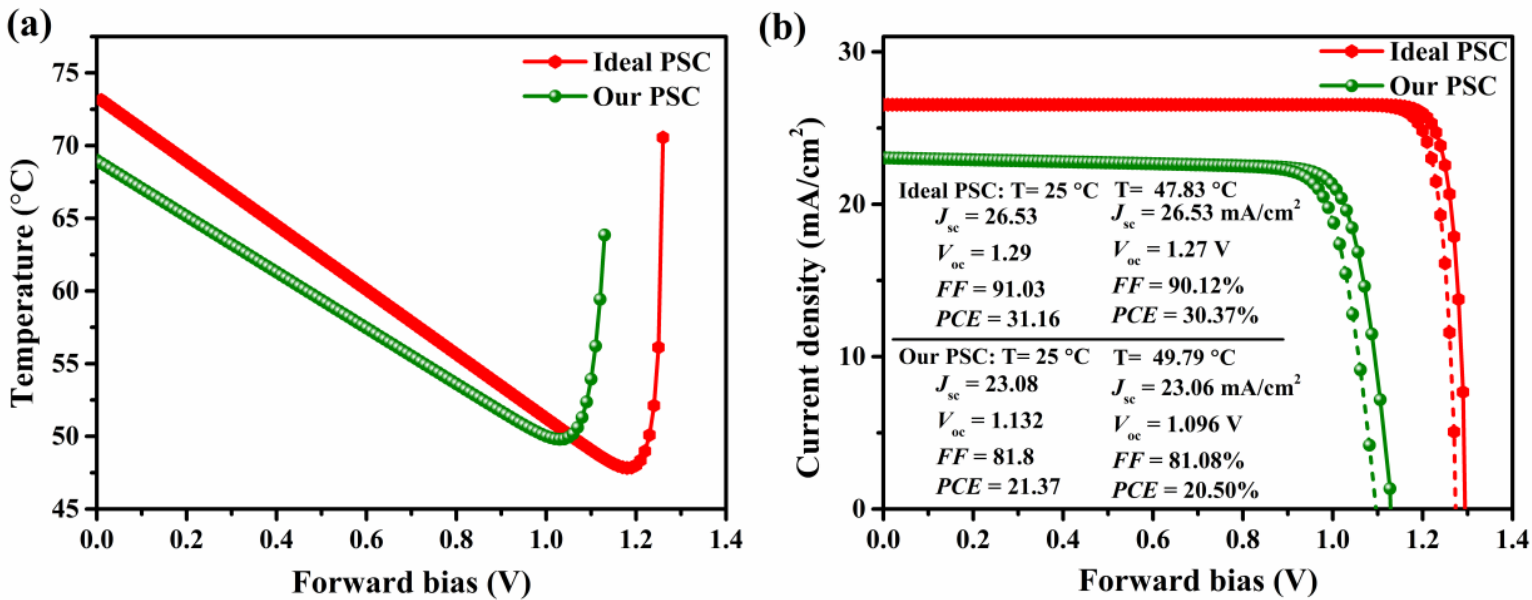

Figure S4. (a) The operating temperature of ideal SC (red line) and our PSC (green line) as a function of the forward bias, respectively. (b) The J-V characteristics under the ambient temperature (solid line) and practical temperature (dot line) for the ideal and our PSCs, respectively. 
The Doping Concentration and Energy Level Alignment Effects on the Performance of PSC

(a)

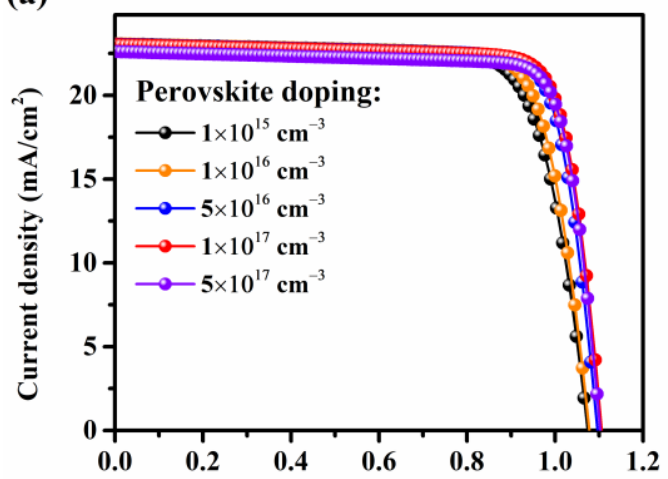

(c)

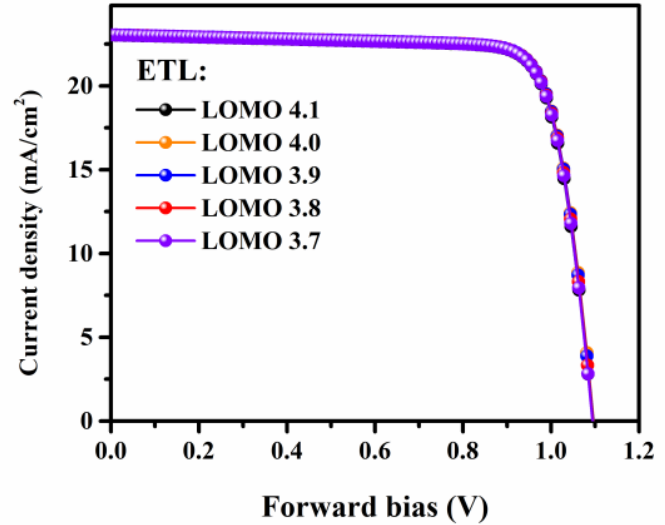

(b)

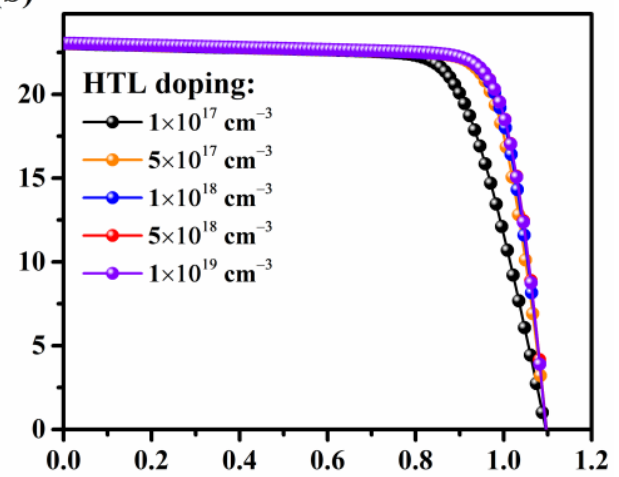

(d)

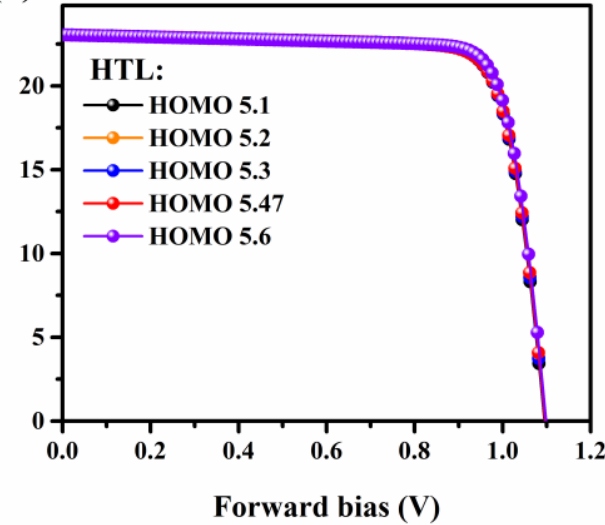

Figure S5. Doping concentration and energy level alignment effect on the IV characteristics.

\section{The EQE Response Spectra of PSC.}

The optimized external quantum efficiency (EQE) is improved to be over $95 \%$ at a broad wavelength range of $450-790 \mathrm{~nm}$.

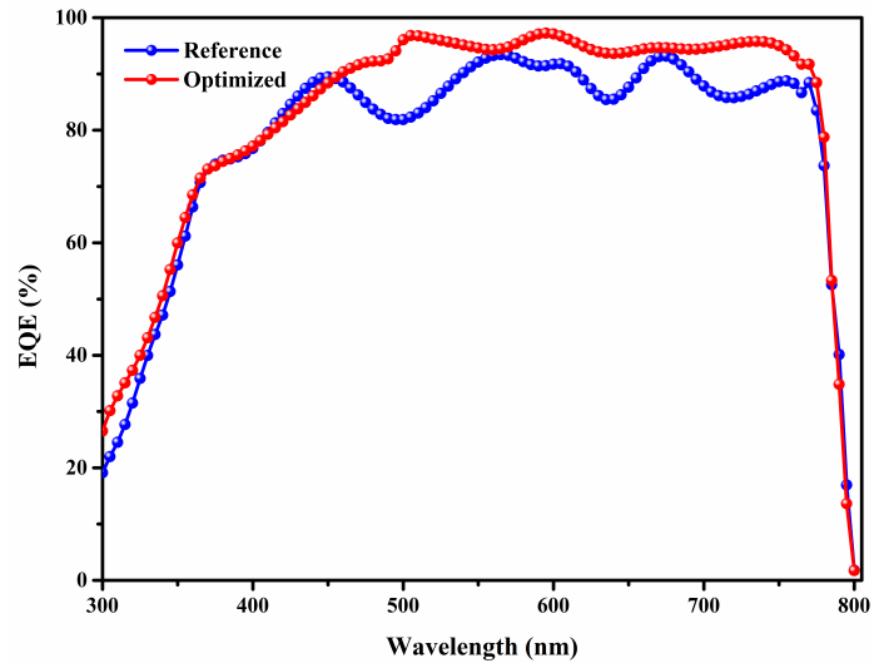

Figure S6. The EQE response spectra of the reference and optimized PSCs. 


\section{Additional Tables}

Key Parameters Used in the OET Simulation of PSC. For the optoelectronic simulation of PSC, the electromagnetic and carrier transportation responses can be adequately obtained by considering the key electrical parameters (e.g., carrier mobility, lifetime) ${ }^{3}$ To focus on the temperature effect on the performance of PSC, the temperature-dependent electrical and thermal simulation parameters should be considered simultaneously in the coupled opto-electro-thermal (OET) model of PSC. We select the (MA) $)_{0.7}(\mathrm{FA})_{0.3} \mathrm{PbI}_{3}$ as the baseline composition to prepare high-performance PSC, its temperature-dependent electrical parameters are listed in Table S1 and thermal simulation parameters (e.g., density, thermal conductivity/capacity) are listed in the Table S2. It should be noted that the parasitic heats generated from the FTO and Au layers also trigger the temperature raise of PSC. Thus, those heats should be considered simultaneously in the thermal simulation.

Table S1. Key Electrical Simulation Parameters. ${ }^{3}$

\begin{tabular}{|c|c|c|c|c|c|c|}
\hline Parameters & Symbol & Unit & ETL & HTL & & Perovskite \\
\hline Electron affinity & $\chi$ & $\mathrm{eV}$ & 4 & 2.5 & 3.9 & $\chi_{0}+1.54 \mathrm{meV}^{*}(\mathrm{~T}-298.15)^{4}$ \\
\hline Band gap & $E_{\mathrm{g}}$ & $\mathrm{eV}$ & 3.4 & 2.7 & 1.57 & $\mathrm{E}_{\mathrm{g} 0}+0.35 \mathrm{meV}^{*}(\mathrm{~T}-298.15)^{4}$ \\
\hline Relative permittivity & $e_{\mathrm{r}}$ & & 9 & 3 & 30 & 30 \\
\hline $\begin{array}{l}\text { Effective DOS for } \\
\text { electron }\end{array}$ & $N_{\mathrm{c}}$ & $\mathrm{cm}^{-3}$ & $9 m_{0}$ & $1 \times 10^{19}$ & $0.23 \mathrm{~m}_{0}$ & $2 *\left(m_{\mathrm{e}} * K_{\mathrm{B}} * \mathrm{~T} / 2 \pi / \hbar^{2}\right)^{1.5}$ \\
\hline Effective DOS for hole & $N_{\mathrm{v}}$ & $\mathrm{cm}^{-3}$ & $3 m_{0}$ & $1 \times 10^{19}$ & $0.29 \mathrm{~m}_{0}$ & $2 *\left(m_{\mathrm{h}} * K_{\mathrm{B}} * \mathrm{~T} / 2 \pi / \hbar^{2}\right)^{1.5}$ \\
\hline Mobility of electron & $\mu_{\mathrm{e}}$ & $\mathrm{cm}^{2} / \mathrm{V} / \mathrm{s}$ & 0.003 & 0.0002 & 12.5 & $\mu_{\mathrm{e} 0} * 10^{4 * \mathrm{~T}^{-1.55}}$ \\
\hline Mobility of hole & $\mu_{\mathrm{h}}$ & $\mathrm{cm}^{2} / \mathrm{V} / \mathrm{s}$ & 0.003 & 0.0002 & 7.5 & $\mu_{\mathrm{h} 0} * 10^{4} * \mathrm{~T}^{-1.55}$ \\
\hline SRH life time & $\tau_{\mathrm{e}}=\tau_{\mathrm{h}}$ & $\mu \mathrm{s}$ & 0.0006 & 0.0001 & 2.1 & $\tau_{0} \times 10 * \mathrm{e}^{(-\mathrm{T} / 120) 5}$ \\
\hline $\begin{array}{c}\text { Radiative recombination } \\
\text { coefficient }\end{array}$ & $B$ & $\mathrm{~cm}^{3} \mathrm{~s}^{-1}$ & 0 & 0 & $3.27 \times 10^{-11}$ & $B_{0} \times 10^{-5 *} \mathrm{e}^{(\mathrm{T} / 27) 5}$ \\
\hline $\begin{array}{l}\text { Auger recombination } \\
\text { coefficient }\end{array}$ & $A_{\mathrm{n}}=A_{\mathrm{p}}$ & $\mathrm{cm}^{6} \mathrm{~s}^{-1}$ & 0 & 0 & $0.88 \times 10^{-29}$ & $A_{0} \times 10^{3 *} \mathrm{e}^{(-\mathrm{T} / 43) 5}$ \\
\hline
\end{tabular}

Table S2. Key Thermal Simulation Parameters.

\begin{tabular}{c|ccccccc}
\hline Parameters & Symbol & Unit & ETL & HTL & Perovskite & FTO & Au \\
\hline Density & $\rho$ & $\mathrm{g} / \mathrm{cm}^{3}$ & 6.95 & $1.2^{8}$ & $4^{9}$ & 6.4 & 19.32 \\
Thermal conductivity & $\kappa$ & $\mathrm{W} / \mathrm{m} / \mathrm{K}$ & $0.65^{6}$ & 0.3 & $0.3^{10}$ & 0.4 & 3.174 \\
Heat capacity & $C_{\mathrm{m}}$ & $\mathrm{J} / \mathrm{g} / \mathrm{K}$ & $1.79^{7}$ & 0.2 & $0.5^{11}$ & 0.4 & 0.126 \\
\hline
\end{tabular}

The temperature-dependent electrical parameters are fitted from the experimental data at the temperature range of $20-70{ }^{\circ} \mathrm{C} .{ }^{4}$ In the simulation, the unit of temperature is Kelvin $(\mathrm{K}), \mu_{\mathrm{e} 0}=6.5 \mathrm{~cm}^{2} / \mathrm{V} / \mathrm{s}, \mu_{\mathrm{h} 0}=3.8 \mathrm{~cm}^{2} / \mathrm{V} / \mathrm{s}$, $\tau_{0}=2530 \mathrm{~ns}, B_{0}=5 \times 10^{-13} \mathrm{~cm}^{3} / \mathrm{s}$, and $A_{0}=1.1 \times 10^{-29} \mathrm{~cm}^{6} / \mathrm{s}$. 
Table S3. Temperature Effect on the Performance of PSC and Carrier Dynamic Characteristics.

\begin{tabular}{|c|c|c|c|c|c|c|c|}
\hline & \multicolumn{6}{|c|}{ Working Temperature $\left({ }^{\circ} \mathrm{C}\right)$} & \multirow[b]{2}{*}{ Linear } \\
\hline & 20 & 30 & 40 & 50 & 60 & 70 & \\
\hline$J_{\mathrm{SC}}(\mathrm{mA} / \mathrm{cm} 2)$ & 23.076 & 23.073 & 23.069 & 23.063 & 23.056 & 23.045 & $-0.061 \% /{ }^{\circ} \mathrm{C}$ \\
\hline$V_{\mathrm{OC}}(\mathrm{V})$ & 1.137 & 1.124 & 1.111 & 1.096 & 1.081 & 1.064 & $-1.45 \mathrm{mV} /{ }^{\circ} \mathrm{C}$ \\
\hline$F F(\%)$ & 82.02 & 81.70 & 81.30 & 81.06 & 80.70 & 80.39 & $-0.033 \% /{ }^{\circ} \mathrm{C}$ \\
\hline$P C E(\%)$ & 21.52 & 21.19 & 20.84 & 20.49 & 20.11 & 19.72 & $-0.036 \% /{ }^{\circ} \mathrm{C}$ \\
\hline SRH & $89.80 \%$ & $87.80 \%$ & $85.90 \%$ & $80.00 \%$ & $77.40 \%$ & $70.40 \%$ & \\
\hline Radiative & $6.20 \%$ & $8.90 \%$ & $11.50 \%$ & $17.70 \%$ & $21.00 \%$ & $28.30 \%$ & \\
\hline Auger & $4.00 \%$ & $3.30 \%$ & $2.60 \%$ & $2.30 \%$ & $1.60 \%$ & $1.30 \%$ & \\
\hline
\end{tabular}

As shown in Table $\mathrm{S} 3$, the specific value that temperature effect on the performance $\left(J_{\mathrm{sc}}, V_{\mathrm{oc}}, F F, P C E\right)$ and carrier recombination mechanisms (SRH, radiative and auger) are listed in the temperature range of $20-70{ }^{\circ} \mathrm{C}$.

\section{References}

(1) An, Y.; Sheng, C.; Li, X. Radiative Cooling of Solar Cells: Opto-Electro-Thermal Physics and Modeling. Nanoscale 2019, 11, 17073-17083.

(2) Shockley, W.; Queisser, H. J. Detailed Balance Limit of Efficiency of $p$ - $n$ Junction Solar Cells. J. Appl. Phys. 1961, 32, 510-519.

(3) An, Y.; Shang, A.; Cao, G.; Wu, S.; Ma, D.; Li, X. Perovskite Solar Cells: Optoelectronic Simulation and Optimization. Sol. RRL 2018, 2, 1800126.

(4) Foley, B. J.; Marlowe, D. L.; Sun, K.; Saidi, W. A.; Scudiero, L.; Gupta, M. C.; Choi, J. J. Temperature Dependent Energy Levels of Methylammonium Lead Iodide Perovskite. Appl. Phys. Lett. 2015, 106, 243904.

(5) Milot, R. L.; Eperon, G. E.; Snaith, H. J.; Johnston, M. B.; Herz, L. M. Temperature-Dependent Charge-Carrier Dynamics in $\mathrm{CH}_{3} \mathrm{NH}_{3} \mathrm{PbI}_{3}$ Perovskite Thin Films. Adv. Fun. Mater. 2015, 25, 6218-6227.

(6) Yu, X.; Wu, Q.; Zhang, H.; Zeng, G.; Li, W.; Qian, Y.; Li, Y.; Yang, G.; Chen, M. Investigation on Synthesis, Stability, and Thermal Conductivity Properties of Water-Based $\mathrm{SnO}_{2} /$ Reduced Graphene Oxide Nanofluids. Mater. 2018, 11, 38.

(7) Yu, J.; Tang, Z.; Wei, G.; Chan, P. C. H. Measurement of Heat Capacity of $\mathrm{SnO}_{2}$ Thin Films Using Micro-Hotplate. Inter. Soc. Opt. Photon. 2001, 4601, 234-237.

(8) Abate, A. A.; Leijtens, T.; Pathak, S.; Teuscher, J.; Avolio, R.; M. E. Errico, Kirkpatrik, J.; Ball, J. M.; Docampo, P.; McPhersonc, I.; Snaith, H. J. Lithium Salts as "Redox Active" p-Type Dopants for Organic 
Semiconductors and Their Impact in Solid-State Dye-Sensitized Solar Cells. Phys. Chem. Chem. Phys. 2013, 15, 2572-2579.

(9) Stoumpos, C. C.; Malliakas, C. D.; Kanatzidis, M. G. Semiconducting Tin and Lead Iodide Perovskites with Organic Cations: Phase Transitions, High Mobilities, and Near-Infrared Photoluminescent Properties. Inorg. Chem. 2013, 52, 9019-9038.

(10) Pisoni, A.; Jacimovic, J.; Barisic, O. S.; Spina, M.; Gaal, R.; Forro, Laszlo; Horvath, E. Ultra-Low Thermal Conductivity in Organic-Inorganic Hybrid Perovskite $\mathrm{CH}_{3} \mathrm{NH}_{3} \mathrm{PbI}_{3}$. J. Phys. Chem. Lett. 2014, 5, $2488-2492$.

(11) Fabini, D. H.; Hogan, T.; Evans, H. A.; Stoumpos, C. C.; Kanatzidis, M. G.; Seshadri, R. Dielectric and Thermodynamic Signatures of Low-Temperature Glassy Dynamics in the Hybrid Perovskites $\mathrm{CH}_{3} \mathrm{NH}_{3} \mathrm{PbI}_{3}$ and $\mathrm{HC}\left(\mathrm{NH}_{2}\right)_{2} \mathrm{PbI}_{3}$. J. Phys. Chem. Lett. 2016, 7, 376-381. 